\title{
Development and Comparison of Fiber-Optic Beta Radiation Sensors with Different Diameters of Their Sensing Probes
}

\author{
Rinah Kim, Sang Bin Lee, Jae Wook Kim, and Joo Hyun Moon \\ Dongguk University, Gyeongju Campus, 123 Dongdae-ro, Gyeongbuk 38066, Republic of Korea \\ Correspondence should be addressed to Joo Hyun Moon; jhmoon86@dongguk.ac.kr
}

Received 20 April 2017; Revised 2 September 2017; Accepted 14 September 2017; Published 18 October 2017

Academic Editor: Andrea Cusano

Copyright (c) 2017 Rinah Kim et al. This is an open access article distributed under the Creative Commons Attribution License, which permits unrestricted use, distribution, and reproduction in any medium, provided the original work is properly cited.

\begin{abstract}
A fiber-optic radiation sensor (FORS) was developed for remote and real-time measurements of beta radiation from radioactivecontaminated soil. The sensing probe consisted of a bundle of organic scintillators and a mixture of epoxy resin to improve the detection efficiency. The measurement system consisted of a sensing probe with an aluminium foil reflector, a transmitting plastic optical fiber, and a light-measuring system comprising a photomultiplier tube, a preamplifier, a multichannel analyzer, and a laptop computer. Several sensing probes, whose dead-end diameters were $26 \mathrm{~mm}$ (bundle type I), $36 \mathrm{~mm}$ (bundle type II), and $46 \mathrm{~mm}$ (bundle type III), were prepared and characterized to identify the best sensing probe in terms of its radiation detection efficiency. The reproducibility of the FORS for the measurement of beta radiation was confirmed using a $\chi^{2}$-test. The measurements showed that the FORS sensing probe with a diameter $46 \mathrm{~mm}$ has the best detection performance.
\end{abstract}

\section{Introduction}

Radioactive-contaminated sites can be released from regulatory control only if the remaining radioactivity is less than the regulatory limit [1]. Prior to its decontamination, the radiation from the site needs be identified, which provides accurate information on the radionuclides to be decontaminated. The radionuclides frequently found at the contaminated sites of foreign nuclear facilities include Am-241, Cs-137, Co-60, H3, I-129, I-131, Pu, Ra, Rn, Sr-90, Tc-99, Th, and U [2]. The radionuclides found at the decommissioned site of an old Korean research reactor, TRIGA MARK III, were Co-60, Cs134, Cs-137, Sr-90, Cr-51, and Fe-59 [3].

Most radionuclides found at the contaminated site are gamma-emitters, but some are beta-emitters that need to be considered in the subsequent decontamination stage. Sr90 , which emits a $0.546 \mathrm{MeV}$ beta particle, has chemical similarity to calcium. The radionuclide accumulates in bones and irradiates the bone marrow causing its high radiotoxicity [4]. Accordingly, this study selected Sr-90 as the target radionuclide to be detected by a fiber-optic radiation sensor (FORS).

Several fiber-optic radiation sensors have been developed for the remote and real-time measurements. Park and Joo developed an underwater beta radiation monitoring sensor using a $\mathrm{CaF}_{2}$ : $\mathrm{Eu}, \mathrm{YAG}$ : Ce, YAP:Ce scintillator [5]. Seo et al. developed a thin film type of plastic scintillation detector [6]. Jang et al. fabricated a fiber-optic radiation sensor for the detection of tritium [7]. Kim et al. developed a $\mathrm{ZnS}(\mathrm{Ag}) / \mathrm{BC}-408$ phoswich detector for monitoring radioactive contamination inside pipes [8]. Hong et al. developed a fiber-optic dual detector to measure beta- and gamma-rays simultaneously [9].

In this study, a FORS was developed for the remote and real-time measurement of beta radiation from radioactivecontaminated soil. The sensing probe consisted of a bundle of organic scintillators and a mixture of epoxy resin to improve its detection efficiency of lights. Several sensing probes, whose dead-end diameters were different, were prepared and characterized to select the best sensing probe in terms of its radiation detection efficiency.

\section{Experimental Setup}

The organic scintillator used was a plastic scintillating fiber (BCF12, Saint-Gobain). Despite being more expensive than a liquid scintillator, the plastic scintillating fiber is chemically 


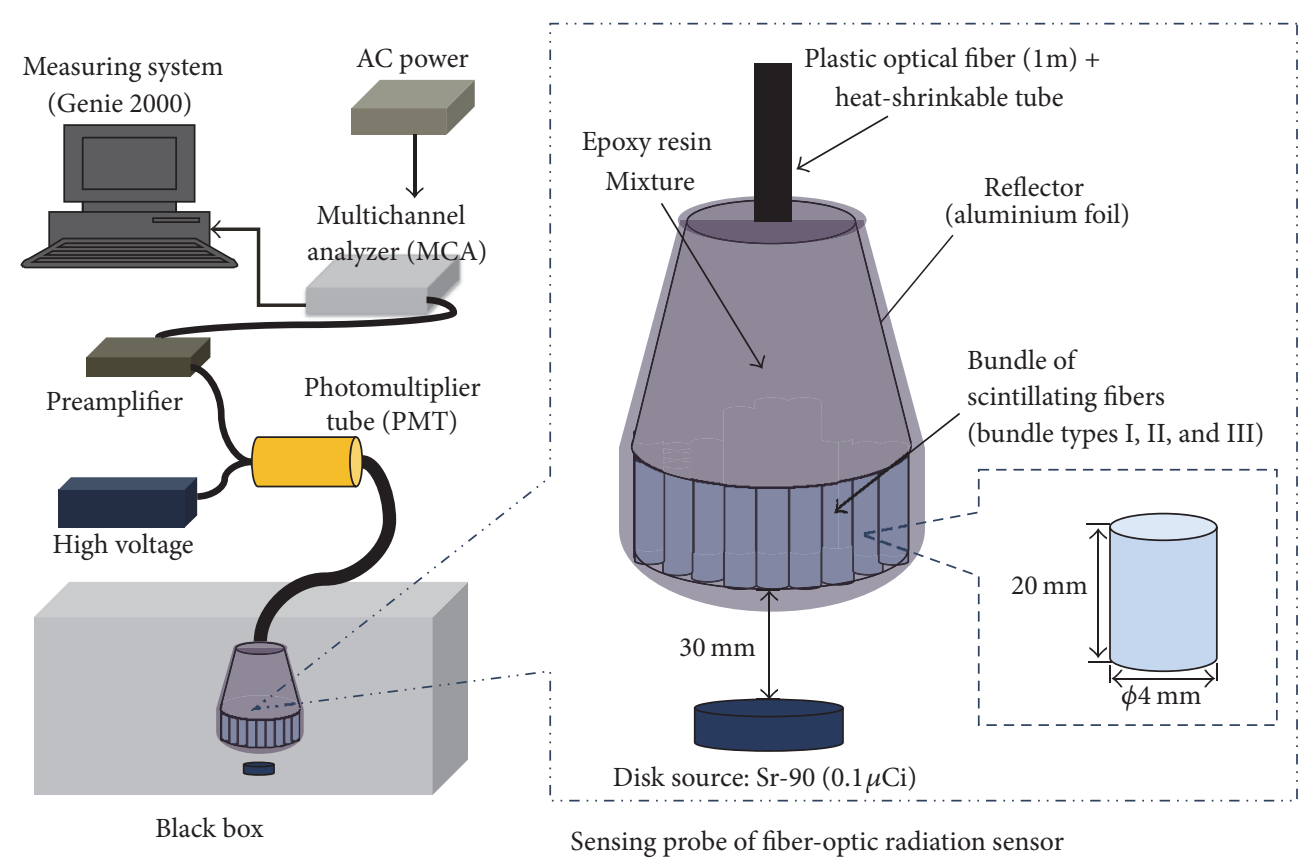

FIgURE 1: Experimental setup for measuring beta radiation.

TABLE 1: Properties of the plastic scintillating fiber (BCF12, SaintGobain).

\begin{tabular}{lccc}
\hline $\begin{array}{l}\text { Emission } \\
\text { peak }(\mathrm{nm})\end{array}$ & $\begin{array}{c}\text { Decay time } \\
(\mathrm{ns})\end{array}$ & 1/e length $(\mathrm{m})$ & $\begin{array}{c}\text { Number of } \\
\text { photons per } \\
\mathrm{MeV}\end{array}$ \\
\hline 435 & 3.2 & 2.7 & $\sim 8000$ \\
\hline
\end{tabular}

stable as a solid material and is easy to fabricate [10]. Table 1 lists its physical properties [11].

The light generated from scintillation was transmitted to the light guide, which was fabricated with transparent epoxy resin that can transmit the light efficiently to the optical fiber owing to its small optical loss resulting from the absorption and leakage of the light. Its characteristics depend on the epoxy resin to hardener mixing ratio. To meet the characteristics required for the light guide, the epoxy resin (YD-128, Kukdo., Korea) and hardener (D-230, Kukdo., Korea) were mixed at a ratio of $5: 1$ [12]. The mixture of epoxy resin was prepared in a truncated conical shape.

Table 2 shows cross-sectional views of two parts of the FORS sensing probes. The overall diameters of the sensing probes were $26 \mathrm{~mm}$ (Bundle type I), $36 \mathrm{~mm}$ (Bundle type II), and $46 \mathrm{~mm}$ (Bundle type III). The bundles of the scintillating fibers were attached to the broader end of the epoxy resin mixture. The sides of the sensing probes were wrapped with aluminium foil ( $3 \mu \mathrm{m}$, Samwha) as a reflector to reduce light leakage.

A plastic optical fiber (\#53-833, Edmund optics) was used as a transmitting optical fiber. The plastic optical fiber has small transmission loss with a peak value of $435 \mathrm{~nm}$. Table 3 lists the properties of the plastic optical fiber.
Figure 1 shows the experimental setup for measuring beta radiation, which consisted of a photomultiplier (PMT, R1924, Hamamatsu), preamplifier (Canberra amplifier model 2006), multichannel analyzer (MCA, Canberra Multiport II), and a laptop computer that was powered by a high-voltage power supplier (Canberra model 3102D). The light transmitted through the transmitting optical fiber to the PMT tube was converted to an electrical signal. This electrical signal was amplified by the preamplifier. The signals were acquired by MCA and analyzed using the GENIE 2000 program installed at the laptop computer.

The FORSs were applied to measure beta radiation from a Sr-90 disk source $(0.1 \mu \mathrm{Ci}, 2014.09$, Spectrum Technique). The FORSs were installed in a dark room to reduce the influences of external light. The sensing probes of the FORS were located $30 \mathrm{~mm}$ above the beta disk source to reduce the effects of backscattered radiation [13]. For comparison, beta radiation from a Sr-90 disk source was also detected using a commercial GM counter (GM214007, NEO).

Because it cannot help being affected by the background radiation, the radiation measurement system should distinguish between background radiation and the radiation to be measured. The critical level $\left(L_{C}\right)$ is defined as the net count rate which must be exceeded before the sample can be said, with a certain level of confidence, to contain measurable radioactivity above background. For the critical level, this paper used (1) to check if the FORS can measure the radiation from the beta source distinguishable from the background radiation, as suggested by [14].

$$
L_{C} \cong 2.33 \sqrt{n_{b}},
$$

where $n_{b}$ is the total background counts. 
TABLE 2: Cross-sectional views of two parts of the FORS sensing probes (unit: $\mathrm{mm}$ ).

Epoxy resin
mixture

TABle 3: Properties of the plastic optical fiber (\#53-833, Edmund optics).

\begin{tabular}{lcccc}
\hline Outer diameter $(\mathrm{mm})$ & Core diameter $(\mu \mathrm{m})$ & Attenuation $(\mathrm{dB} / \mathrm{km})$ & Numerical aperture $(\mathrm{NA})$ & Operating temperature $\left({ }^{\circ} \mathrm{C}\right)$ \\
\hline 3 & 2,950 & $150 \sim 300(@ 650 \mathrm{~nm})$ & 0.50 & $-55 \sim 70$ \\
\hline
\end{tabular}

TABLE 4: Comparison of the measurements by the commercial detector and FORSs.

\begin{tabular}{lcccc}
\hline Detector & Background counts & Critical level $\left(L_{c}\right)$ & Total counts & Counts per second \\
\hline $\begin{array}{l}\text { Commercial detector } \\
\text { (GM counter) }\end{array}$ & 273 & 38.49 & 56967 & $94.49 \pm 0.45$ \\
FORS with $26 \mathrm{~mm}$ & 12367 & 259.11 & 15341 & $25.57 \pm 0.40$ \\
FORS with $36 \mathrm{~mm}$ & 12915 & 264.79 & 16543 & $27.57 \pm 0.32$ \\
FORS with $46 \mathrm{~mm}$ & 13274 & 268.45 & 17004 & $28.34 \pm 0.20$ \\
\hline
\end{tabular}

\section{Results and Discussion}

Figure 2 shows the measurements by the FORSs with the three different diameters. Each measurement by each FORS was made for over 600 seconds and repeatedly 20 times. The total counts in Table 4 are the average of the 20 measurements obtained by using the FORSs. The total counts by the FORSs with $26 \mathrm{~mm}, 36 \mathrm{~mm}$, and $46 \mathrm{~mm}$ in diameter were 15341, 16543 , and 17004, respectively, which are summarized in Table 4, along with other measurement values. The FORS detected more radiation from the source as the diameter of its sensing probe was increased. For the bundle type III of the sensing probe, the peak values were higher than the other two sensing probes. Compared to that by using a commercial
GM counter for over 600 seconds, the relative total counts obtained by using the FORSs with a diameter of $26 \mathrm{~mm}$, $36 \mathrm{~mm}$, and $46 \mathrm{~mm}$ were found to be $26.9 \%, 29.0 \%$, and $29.8 \%$, respectively.

The reproducibility of the FORS was tested by applying a $\chi^{2}$-test to the measurements as a minimum requirement for a radiation sensor. Because radioactive decay is a random process, any measurement of radiation is subject to a degree of the statistical fluctuation. A $\chi^{2}$-test is constructed from a sum of squared errors or through the sample variance. If the probability for the estimated $\chi^{2}$ is in the range of $0.1<p<$ 0.9 , it can be determined that the radiation detection system produces reproducible measurement reflecting the statistical fluctuations of radioactive decay appropriately [15-18]. 


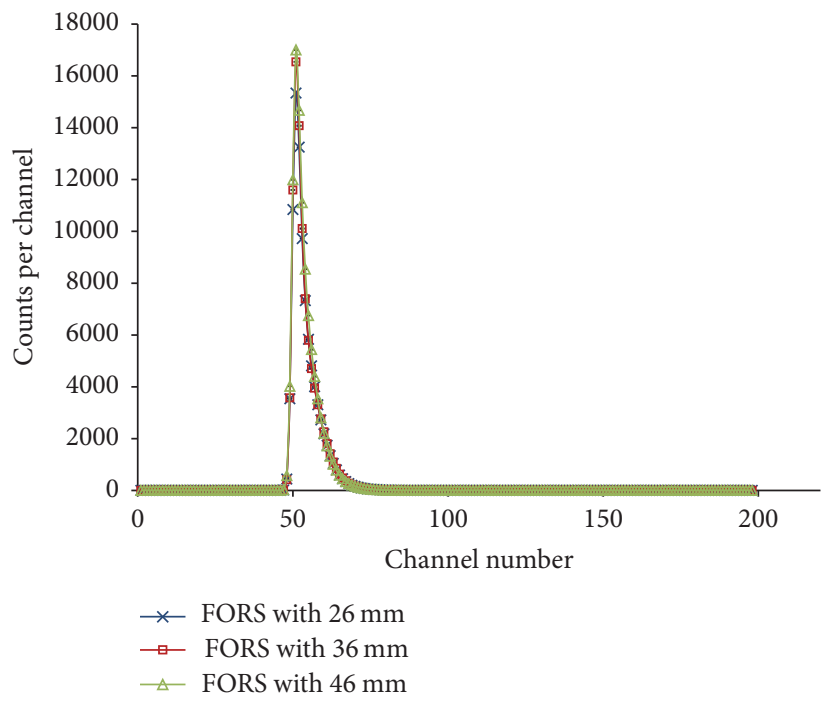

(a)

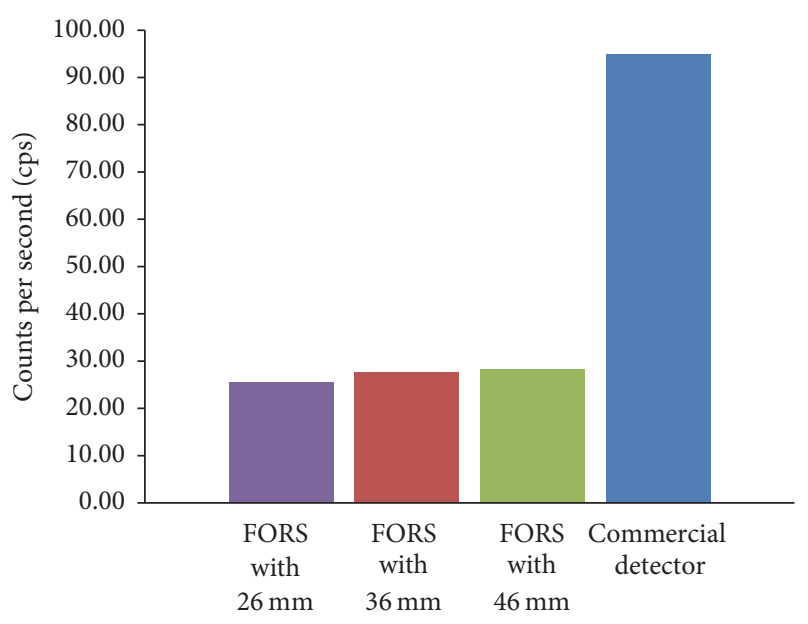

(b)

FIGURE 2: Comparison of (a) pulse height spectra and (b) measurements (cps) by the FORSs with different diameters and a commercial GM counter.

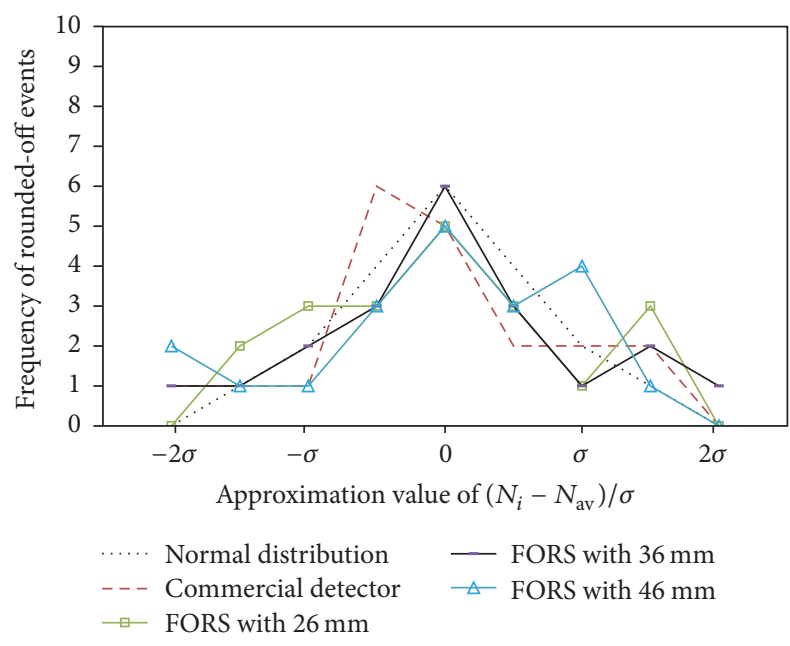

FIGURE 3: Distributions of a statistic $\left(N_{i}-N_{\mathrm{av}}\right) / \sigma$ for 20 measurements by the FORSs and a commercial GM counter.

Table 5 lists the 20 measurements by each FORS and the relevant statistics for the $\chi^{2}$-test. The $\chi^{2}$ s for the measurements by the FORSs were 19.72, 18.55, and 14.70 for a diameter of $26 \mathrm{~mm}, 36 \mathrm{~mm}$, and $46 \mathrm{~mm}$, respectively. The probabilities of $\chi^{2}$ s with 19 degrees of freedom were 0.54 , 0.51 , and 0.76 , respectively. Figure 3 shows the distributions of a statistic $\left(N_{i}-N_{\mathrm{av}}\right) / \sigma$, where $N_{i}$ is $i$ th measurement by the FORSs and GM counter, $N_{\mathrm{av}}$ is the average, and $\sigma$ is the standard deviation of the 20 measurements. Figure 3 helps to check intuitively if the FORSs generate the statistically significant measurements, showing the difference between the distributions of the statistic and the normal distribution.
TABLE 5: The 20 measurements by the FORSs with different diameters and the relevant statistics.

\begin{tabular}{lccc}
\hline $\begin{array}{l}\text { Number of } \\
\text { measurements }\end{array}$ & $\begin{array}{c}\text { FORS with } \\
26 \mathrm{~mm}\end{array}$ & $\begin{array}{c}\text { FORS with } \\
36 \mathrm{~mm}\end{array}$ & $\begin{array}{c}\text { FORS with } \\
46 \mathrm{~mm}\end{array}$ \\
\hline$(1)$ & 15244 & 16521 & 16781 \\
$(2)$ & 15369 & 16406 & 17039 \\
$(3)$ & 15540 & 16553 & 17120 \\
$(4)$ & 15188 & 16744 & 16919 \\
$(5)$ & 15406 & 16556 & 17012 \\
$(6)$ & 15256 & 16491 & 16859 \\
$(7)$ & 15340 & 16781 & 17011 \\
$(8)$ & 15233 & 16512 & 17142 \\
$(9)$ & 15499 & 16352 & 17096 \\
$(10)$ & 15533 & 16652 & 17102 \\
$(11)$ & 15171 & 16581 & 17017 \\
$(12)$ & 15396 & 16566 & 16988 \\
$(13)$ & 15128 & 16279 & 16965 \\
$(14)$ & 15273 & 16522 & 17108 \\
$(15)$ & 15351 & 16588 & 17165 \\
$(16)$ & 15406 & 16535 & 16948 \\
$(17)$ & 15359 & 16571 & 16759 \\
$(18)$ & 15552 & 16751 & 17004 \\
$(19)$ & 15351 & 16409 & 16926 \\
$(20)$ & 15226 & 16498 & 17114 \\
\hline Average & 15341 & 16543 & 17004 \\
$\chi^{2}$ & 19.72 & 18.55 & 14.70 \\
$p$ & 0.54 & 0.51 & 0.76 \\
\hline
\end{tabular}

\section{Conclusion}

This study developed and characterized a FORS for the remote and real-time measurements of beta radiation. The 
FORS consisted of the sensing probe with an aluminium foil reflector, transmitting plastic optical fiber, and lightmeasuring system that comprised a photomultiplier tube, preamplifier, multichannel analyzer, and laptop computer. The measurements showed that the FORS could be used as a radiation sensor and that the FORS sensing probe with a diameter $46 \mathrm{~mm}$ has the best detection performance.

\section{Conflicts of Interest}

The authors declare that they have no conflicts of interest.

\section{Acknowledgments}

This study was supported by a National Research Foundation of Korea (NRF) grant funded by the Korea government, Ministry of Science, ICT and Future Planning (MSIP, Research Project no. 2012M2B2B1055499).

\section{References}

[1] "U. S. Nuclear Regulatory Commission," 10 CFR part 20standards for protection against radiation.

[2] L. E. Boing, Introduction to decommissioning, Argone National Laboratory, 2013.

[3] G. N. Kim et al., "Methods of recycling soil washing wastewater for volume reduction," Journal of KoSSGE, vol. 8, pp. 17-26, 2003.

[4] S. K. Sahoo, N. Kavasi, A. Sorimachi et al., "Strontium-90 activity concentration in soil samples from the exclusion zone of the Fukushima daiichi nuclear power plant," Scientific Reports, vol. 6, Article ID 23925, pp. 1-10, 2016.

[5] H. M. Park and K. S. Joo, "Feasibility Study on Development of an Underwater Beta-ray Monitoring Sensor," Journal of Sensor Science and Technology, vol. 25, no. 5, pp. 333-336, 2016.

[6] B. K. Seo, Z. H. Woo, W. Z. On, K. W. Lee, and M. J. Han, "Preparation of a thin film type of plastic scintillation detector for betaray detection," Analytical science and Technology, vol. 18, pp. 495-499, 2005.

[7] K. Jang, D. Cho, W. Yoo et al., "Fabrication and Characterization of a Fiber-optic Radiation Sensor for Detection of Tritium," Korean Journal of Optics and Photonics, vol. 20, no. 4, pp. 201206, 2009.

[8] G. H. Kim, C. H. Park, C. H. Jung, K. W. Lee, and B. K. Seo, "Development of the $\mathrm{ZnS}(\mathrm{Ag}) / \mathrm{BC}-408$ phoswich detector for monitoring radioactive contamination inside pipes," Journal of the Korean association for radiation protection, vol. 31, pp. 123$128,2006$.

[9] S. Hong, S. H. Shin, H. I. Sim et al., "Feasibility study on development of a fiber-optic dual detector to measure beta- And gamma-rays simultaneously," The Transactions of Korean Institute of Electrical Engineers, vol. 63, no. 2, pp. 284-290, 2014.

[10] K. Han, W. Yoo, S. Shin et al., "Development of Fiber-optic Radiation Sensor Using LYSO Scintillator for Gamma-ray Spectroscopy," Journal of Sensor Science and Technology, vol. 21, no. 4, pp. 287-292, 2012.

[11] D. L. Chichester, S. M. Watson, and J. T. Johnson, "Comparison of bcf-10, bcf-12, and bcf-20 scintillating fibers for use in a 1-dimensional linear sensor," IEEE Transactions on Nuclear Science, vol. 60, no. 5, pp. 4015-4021, 2013.
[12] C. H. Park, J. H. Moon, and B. K. Seo, "Development and characterization of the integrated fiber-optic sensor for remote detection of alpha radiation," Journal of the Korean Physical Society, vol. 63, no. 9, pp. 1720-1723, 2013.

[13] H. Joo, R. Kim, and J. H. Moon, "Radioactivity measurement of radioactive contaminated soil by using a fiber-optic radiation sensor," Journal of the Korean Physical Society, vol. 68, no. 11, pp. 1287-1290, 2016.

[14] J. E. Martin, Hysics for Radiation Protection: A Handbook, Wiley-VCH, Berlin, Germany, 2 edition, 2006.

[15] G. F. Knoll, Radiation Detection and Measurement, John Wiley and Sons, New York, NY, USA, 3 edition.

[16] N. Tsoulfanidis, Measurement and Detection of Radiation, Hemisphere, Washington DC, USA, 1983.

[17] P. R. Bevington, Data reduction and error analysis for the physical sciences, McGraw-Hill, New York, NY, USA, 1969.

[18] D. M. Namuth-covert, "Chi-square test for goodness of fit in a plant breeding example," Plant \& Soil Sciences eLibrary ${ }^{P R O}$. 


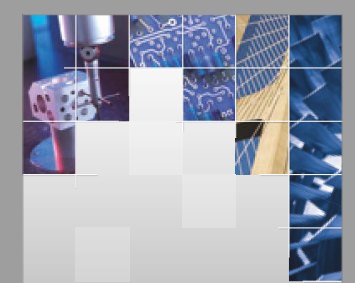

\section{Enfincering}
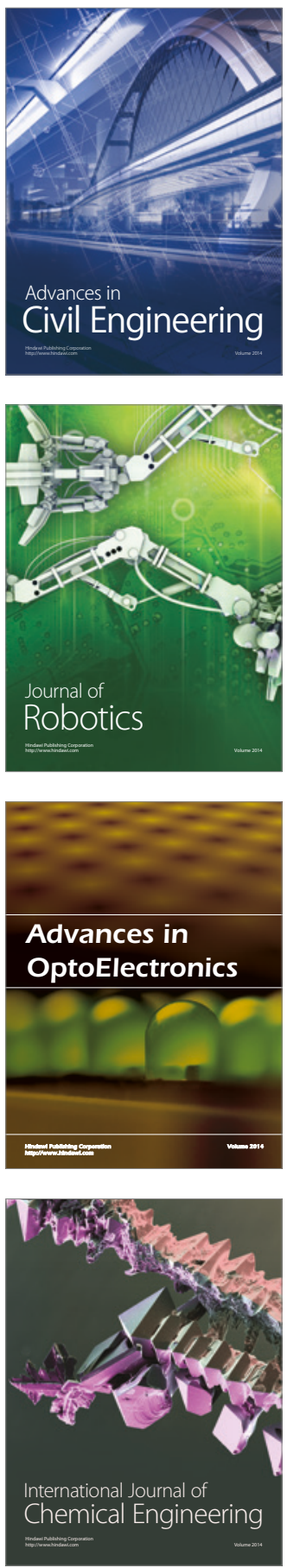

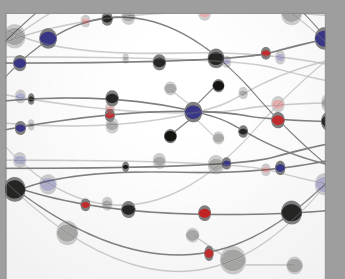

The Scientific World Journal

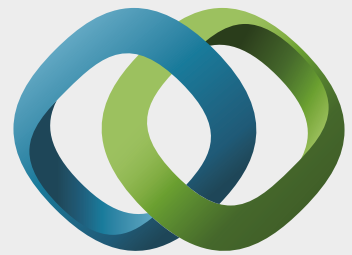

\section{Hindawi}

Submit your manuscripts at

https://www.hindawi.com
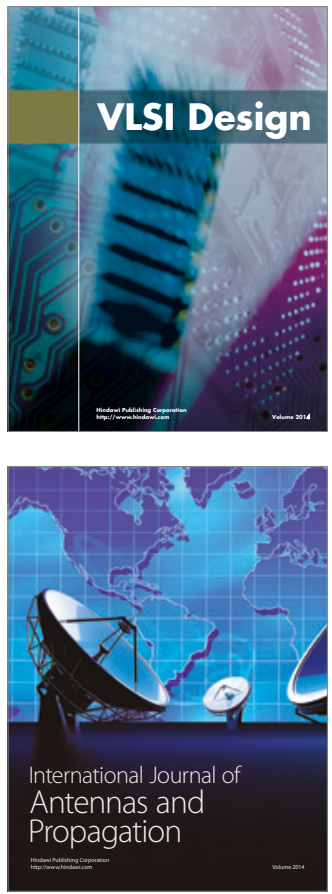

\section{Rotating}

Machinery
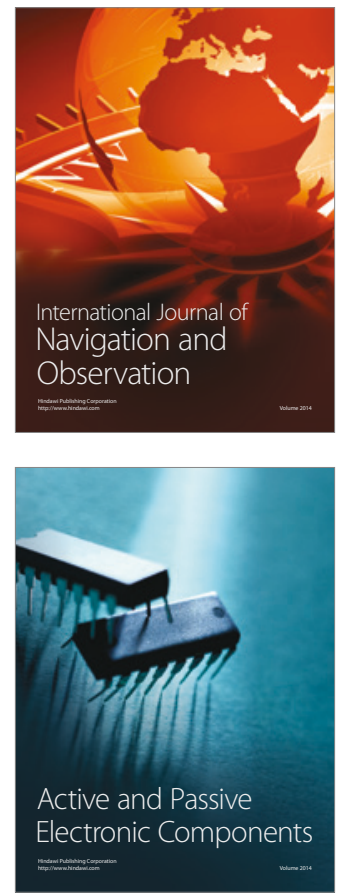
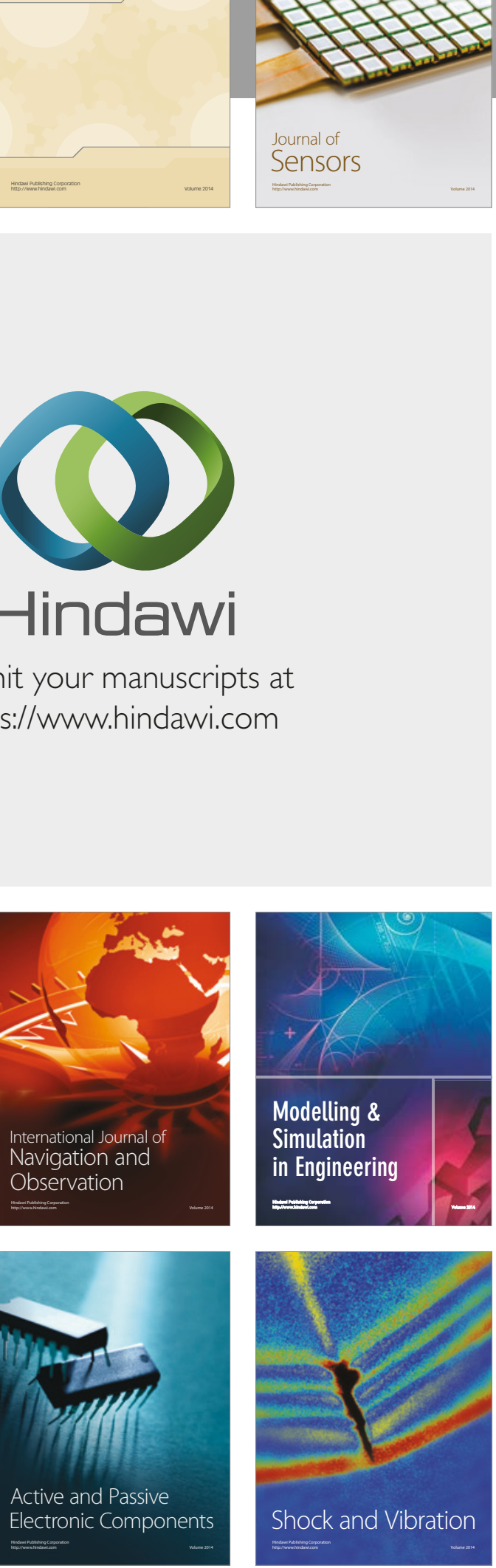
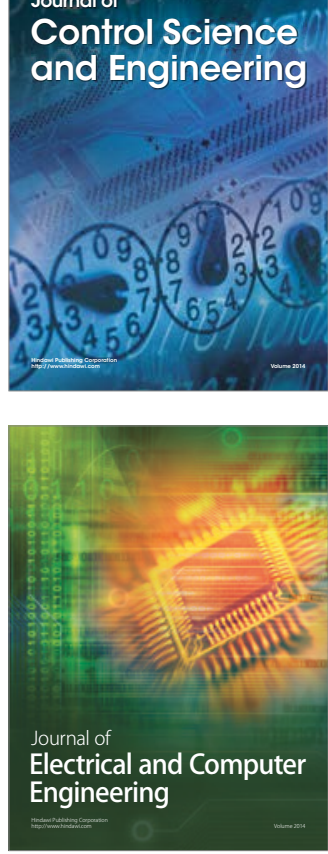

Distributed

Journal of

Control Science

and Engineering
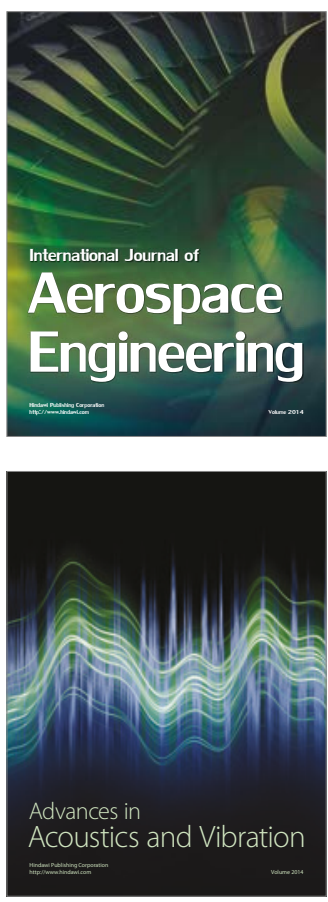

Sensor Networks 